\title{
BMJ Open Effectiveness of multicomponent interventions in primary healthcare settings to promote continuous smoking cessation in adults: a systematic review
} Carlos Martín Cantera, ${ }^{1,2,3}$ Elisa Puigdomènech, ${ }^{1}$ Jose Luis Ballvé, ${ }^{4}$
Olga Lucía Arias, ${ }^{4}$ Lourdes Clemente, ${ }^{5}$ Ramon Casas, ${ }^{6}$ Lydia Roig, ${ }^{7,8}$
Santiago Pérez-Tortosa, ${ }^{9}$ Laura Díaz-Gete, ${ }^{10}$ Sílvia Granollers ${ }^{11}$
To cite: Martín Cantera C, Puigdomènech $\mathrm{E}$, Ballvé $\mathrm{JL}$, et al. Effectiveness of multicomponent interventions in primary healthcare settings to promote continuous smoking cessation in adults: a systematic review. BMJ Open 2015;5:e008807. doi:10.1136/bmjopen-2015008807

- Prepublication history and additional material is available. To view please visit the journal (http://dx.doi.org/ 10.1136/bmjopen-2015008807)

Received 19 May 2015 Revised 31 August 2015 Accepted 9 September 2015

CrossMark

For numbered affiliations see end of article.

Correspondence to Elisa Puigdomènech; cardiocat@gmail.com

\section{ABSTRACT}

Objective: The objective of the present review is to evaluate multicomponent/complex primary care (PC) interventions for their effectiveness in continuous smoking abstinence by adult smokers.

Design: A systematic review of randomised and nonrandomised controlled trials was undertaken.

Eligibility criteria for included studies: Selected studies met the following criteria: evaluated effects of a multicomponent/complex intervention (with 2 or more intervention components) in achieving at least 6-month abstinence in adult smokers who visited a PC, biochemical confirmation of abstinence, intention-totreat analysis and results published in English/Spanish. Methods: We followed PRISMA statement to report the review. We searched the following data sources: MEDLINE, Web of Science, Scopus (from inception to February 2014), 3 key journals and a tobacco research bulletin. The Scottish Intercollegiate Guidelines Network checklists were used to evaluate methodological quality. Data selection, evaluation and extraction were done independently, using a paired review approach. Owing to the heterogeneity of interventions in the studies included, a meta-analysis was not conducted.

Results: Of 1147 references identified, 9 studies were selected (10 204 participants, up to 48 months of follow-up, acceptable methodological quality). Methodologies used were mainly individual or group sessions, telephone conversations, brochures or quitsmoking kits, medications and economic incentives for doctors and no-cost medications for smokers. Complex interventions achieved long-term continuous abstinence ranging from $7 \%$ to $40 \%$. Behavioural interventions were effective and had a dose-response effect. Both nicotine replacement and bupropion therapy were safe and effective, with no observed differences.

Conclusions: Multicomponent/complex interventions in PC are effective and safe, appearing to achieve greater long-term continuous smoking cessation than usual care and counselling alone. Selected studies were heterogeneous and some had significant losses to follow-up. Our results show that smoking

\section{Strengths and limitations of this study}

- Our systematic review shows that multicomponent primary care interventions yield feasible, effective, safe smoking cessation.

- Multiple component primary care interventions best achieve long-term continuous abstinence.

- Multiple component strategies should include setting a 'D-day' and drug therapies.

- Despite the rather strict inclusion criteria of the present review, we found quite high heterogeneity in the results.

- Most essential components of the interventions studied are not clearly established.

interventions should include more than one component and a strong follow-up of the patient to maximise results.

\section{BACKGROUND}

Tobacco use continues to be the primary cause of premature and overall mortality worldwide, ${ }^{1}$ and treating the smoker is considered the 'gold standard' for the prevention of chronic diseases. ${ }^{2} 3$ Healthcare interventions are low cost in relation to the gains achieved in quality and years of life. From the public health point of view, the results obtained may constitute the most costeffective means of improving the health of a population. ${ }^{3-6}$ Smoking cessation interventions carried out by health professionals have been shown to increase abstinence rates. ${ }^{7-10}$ A minimum of smoking cessation counselling achieves an average of $5 \%$ cessation in the general population per year; ${ }^{11}$ if combined with intensive follow-up, this rate can exceed $20 \% .^{12}{ }^{13}$ When health professionals offer assistance and support to break the 
habit, the likelihood of smoking cessation increases; furthermore, this effect increases with the frequency and duration of the interventions. In general, the proportion of abstention increases with the intensity of the intervention, the time spent, and the number and diversity of contacts, including follow-up visits. ${ }^{12}$ On the other hand, various systematic reviews and meta-analyses have shown the utility of applying treatments with demonstrated efficacy. ${ }^{5} 1415$

Interventions undertaken to promote smoking cessation, as well as other healthy behaviours, imply a wide spectrum of complexity, due to numerous factors: (1) the number and difficulty of the behaviours required of participants, (2) the diverse types of professionals who apply the intervention, (3) the existence of diverse, separate components that can act independently of and interact with each other, (4) numerous variables with diverse degrees of difficulty in their measurement, (5) number and variability of outcomes, (6) changeable and dynamic environments, and (7) the need for flexibility and adjustment of the interventions. This complexity exerts a deep influence on the design of these interventions, and the methodology, the measurements, the analysis and the results of these initiatives. ${ }^{16-18}$ In addition to dissemination in scientific journals, these interventions should be adapted to different settings and feasible to implement. ${ }^{19}$ According to Grandes et $a l^{20}$, multicomponent interventions are becoming more frequent, and offer a promising new alternative in improving lifestyle behaviours such as smoking cessation. Systematic reviews that assemble scientific analysis on the efficiency of the simple interventions are abundant; in contrast, the syntheses of the results of more complex interventions are scarce, although lately they have been attracting great interest. ${ }^{162122}$

A 'complex intervention' is quite hard to define precisely and can sometimes be difficult to distinguish from a simple one; moreover, we have not found a clear definition for this term. ${ }^{16}{ }^{23}$ Complexity can be explained for several different factors. ${ }^{18}$ We understand the term 'complex intervention' as those interventions with at least two interacting components, such as procedures (email tracking, for instance), behaviours (individual or groupal interventions, for instance) or products (medicines). ${ }^{16} 21$

The purpose of the present paper is to undertake a systematic review focused on multicomponent interventions, with the aim to offer a tool that could be useful both to researchers and general practitioners in the primary care setting. The specific objective of this study is to determine the effectiveness of these interventions in achieving continuous tobacco abstinence in smokers aged 18 or older in the primary care setting. In order to make the findings more practical and applicable, our search strategy was focused on primary care setting. Primary care is the most adequate and important setting to implement interventions, to help smokers quit, because most smokers visit their primary care professionals at least once a year ${ }^{524}$ and is the healthcare level that can systematically integrate the methodologies for health promotion and disease promotion.

\section{METHODS}

The Preferred Reporting Items for Systematic Reviews and Meta-Analyses (PRISMA) statement was used as a guide for reporting this review. ${ }^{26}$

\section{Eligibility criteria}

Articles included in this review met the Population, Intervention, Comparison, Outcome (PICO) criteria contained in WHO guidelines. Selected studies met the following criteria: evaluated the effects of interventions with at least two interacting components in individuals older than 18 years who smoke any quantity of tobacco and receive primary care. Smoking cessation was considered by achieving at least 6 months of continuous smoking abstinence, verified biochemically. The definition of continuous smoking abstinence was based on that proposed by Hughes et $a l^{27}$ in 2003: a period of total abstinence between a quit date and a follow-up evaluation. We selected randomised controlled trials (RCT) or non-RCTs, published in English or Spanish, which included interventions with at least two components, designed to help patients stop smoking and took an intention-to-treat (ITT) approach. Studies were excluded that were carried out only in adolescents $(<18$ years old $)$, did not report continuous abstinence ( $\geq 6$ months), were not carried out in the primary care setting or did not analyse the data by ITT. Data from individuals with certain diseases (eg, cardiovascular disease or diabetes) and specific sectors of the population (eg, pregnant women) were included if the study had been carried out in the primary care setting.

\section{Information sources}

Searches were conducted in three databases, MEDLINE (via PubMed), Web of Science and SCOPUS, and supplemented with a manual search of the archives of three key journals: Addiction, Tobacco Control, and Nicotine and Tobacco Research. In addition, the periodic alerts from Smoking and Tobacco Abstracts and News (STAN Bulletin) ${ }^{28}$ were searched, followed by a reverse search based on references cited in the key articles recovered using the initial search strategy. The search period extended from the inception of the database or journal through the end of February 2014. The entire search process was supported by bibliographic specialists of the School of Medicine, Universitat Autònoma de Barcelona.

\section{Search}

The search strategy combined a controlled vocabulary and free-text terms; the full strategy used for MEDLINE (via PubMed) is described in online supplementary annex 1. 


\section{Study selection and data collection process}

All references identified in the different databases were imported into Reference Manager (V.12), and duplicate bibliographic records were eliminated.

Ten reviewers participated in the selection process. Each article identified was randomly assigned to two reviewers, who independently reviewed the title and abstract to identify articles meeting the inclusion criteria for full-text review. Each reviewer received the basic citation data, the abstract and an Excel database containing the fields to be considered (study population, primary care setting, type of intervention and results obtained). Any disputed selections were resolved by a third reviewer.

Two different reviewers evaluated the full text of the selected articles to confirm their eligibility according to the inclusion criteria. In case of any disagreement, a third reviewer made the final decision. An ad hoc form was designed to extract data from the full text of the selected articles.

\section{Risk of bias in studies}

To assess the methodological quality of the selected studies, the SIGN (Scottish Intercollegiate Guidelines Network) checklist for RCTs was used, along with a version of the SIGN guidelines adapted for nonrandomised studies (see online supplementary annex $2)$. The quality review included 10 general items and overall evaluation item that classified each study as high quality, acceptable or low quality. A study was considered high quality if it met the majority of the criteria, showed little or no risk of bias, and the results seemed unlikely to change due to additional research. Quality was considered acceptable if most criteria were met but there were some flaws and an associated risk of bias, and further study could change the reported conclusions. Studies that failed to meet the majority of the criteria, had major flaws, and whose conclusions were likely to change in light of further studies were considered low quality and excluded from analysis.

\section{Synthesis of results}

The present review is narrative because of the great heterogeneity of the studies included. Differences in the age of participants, populations studied, diversity in statistics and outcome measures made unfeasible to report a global effect size. Moreover, the type and duration of the interventions and follow-up varied widely among the studies, and consequently a formal meta-analysis to combine study results was not possible. The results of the selected studies were summarised in tables that show the years of the study, the population, type of study, type of intervention, major results, author conclusions and methodological quality of the study.

\section{RESULTS}

\section{Study selection}

A total of 1651 records were collected, of which 504 $(30.5 \%)$ were identified as duplicates. Once the independent paired review of the 1147 records was completed, $1026(89.5 \%)$ were excluded from further analysis. Of the 121 publications selected, 4 were rejected after a second paired review of the corresponding abstract. Full-text review was completed for 117 (96.7\%) articles. After paired review, 10 publications (9 studies) were finally included in the present narrative review. The reasons for discarding articles at the first and second levels of paired review are shown in figure 1 .

\section{Study characteristics}

The primary characteristics of the nine studies included in the present review, as well as the major results and conclusions are detailed in table 1 (panels A and B). Eight studies are RCTs and one is a non-RCT. ${ }^{29}$ Two publications refer to different aspects of the same RCT. $^{30}{ }^{31}$ Inclusion periods ranged from the mid-1990s to the first decade of the 21st century. Five of the studies were carried out in the Spanish population and the remainder in the German population, ${ }^{32}$ the $\mathrm{USA}^{33}$ China ${ }^{34}$ and Holland. ${ }^{35}$ Of the nine studies included, eight were carried out in the general population and one in patients with chronic obstructive pulmonary disease. ${ }^{34}$ The number of smokers participating ranged from 89 in Spain $^{36}$ to 3562 in China. ${ }^{34}$ The selected studies included a total of 10204 participants and the follow-up varied from 6 to 48 months. Some studies included smokers of any quantity of cigarettes, while Twardella and Brenner included only those who smoked more than 10 cigarettes daily and Daughton et $a \hat{l}^{33}$ required 20 cigarettes daily for inclusion. Six studies had a control group receiving usual care, and all nine compared at least two groups. The measurement of exhaled carbon monoxide $(\mathrm{CO})$ was the main biochemical means of confirming abstinence; only two studies ${ }^{35}$ measured cotinine, in urine and saliva, respectively.

In some trials, the intervention occurred with smokers at the preparation phase, ${ }^{29} 343537$ which generally, but not always, increased the number who quit smoking and decreased the number who abandoned. The trial by Cabezas $e t a l^{30}$ and Puente $e t a l^{31}$ included smokers at all stages of the change process. In the study by Torrecilla et $a l^{38}$ despite focusing on a population at all stages of change, patients in the preparation phase were accepted as referrals from other practices.

\section{Risk of bias within studies}

All of the studies obtained an 'acceptable' quality score (table 2). The major quality problems were the lack of blind interventions and the heterogeneity of losses to follow-up, ranging from $1.2 \%$ to $76 \%$; in fact, three of the studies ${ }^{30} 313537$ reported more than $40 \%$ loss to follow-up and a lack of blinding in the interventions. All of the studies applied ITT analysis (loses to follow-up were considered as smokers). All of the selected studies, as expected because it was a criterion for inclusion, confirmed tobacco abstinence by some biochemical test. 
Table 1 Major characteristics of the articles included in the review of complex interventions to promote smoking cessation

\begin{tabular}{|c|c|c|c|c|}
\hline \multicolumn{5}{|l|}{ Panel A } \\
\hline $\begin{array}{l}\text { Reference (year } \\
\text { of publication) }\end{array}$ & $\begin{array}{l}\text { Type of } \\
\text { study }\end{array}$ & $\begin{array}{l}\text { Study population } \\
\text { (inclusion criteria, study location) }\end{array}$ & $\begin{array}{l}\text { Key elements of } \\
\text { intervention }\end{array}$ & Type of intervention \\
\hline $\begin{array}{l}\text { Daughton et al } \\
(1998)^{33}\end{array}$ & $\mathrm{RCT}$ & $\begin{array}{l}369 \text { smokers of } 20 \text { or more cigarettes/day, } \\
\text { aged } 19-65 \text { years recruited in Nebraska } \\
\text { (USA). Period NS }\end{array}$ & $\begin{array}{l}\text { Presential visits } \\
\text { Professional } \\
\text { training } \\
\text { Medication }\end{array}$ & $\begin{array}{l}\text { Control group: two primary care visits devoted to smoking cessation } \\
\text { and } 10 \text { weeks of wearing a placebo patch } \\
\text { Intervention group: two primary care visits devoted to smoking } \\
\text { cessation and } 10 \text { weeks of wearing a nicotine patch } \\
\text { Set a D-day. Contacted participants for follow-up visits at } 3,6 \text { and } \\
12 \text { months after D-day ( } 4 \text { visits). Training was provided, although the } \\
\text { authors do not indicate its duration. Intervention model not described }\end{array}$ \\
\hline $\begin{array}{l}\text { Grandes et al } \\
(2000)^{29}\end{array}$ & Non-RCT & $\begin{array}{l}1768 \text { smokers in the preparation phase of } \\
\text { change; primary care patients in the Basque } \\
\text { Country (Spain) in 1995-1996 }\end{array}$ & $\begin{array}{l}\text { Presential visits } \\
\text { Telephone calls } \\
\text { Medication }\end{array}$ & $\begin{array}{l}\text { Control group: usual care } \\
\text { Intervention group: intervention based on clinical practice } \\
\text { recommendations and based on identifying smokers, advise them } \\
\text { about smoking cessation, help them through motivational interview to } \\
\text { stop smoking, encourage the use of NRT to stop smoking and } \\
\text { schedule follow-up visits } \\
\text { Training ( } 20 \mathrm{~h} \text { ) provided for all participants. Intervention group } \\
\text { participates in } 3 \text { office visits. The time the doctor spends on each } \\
\text { visit was measured in a sample of } 50 \text { visits: } 23 \mathrm{~s} \text { were spent } \\
\text { identifying the smoker; } 3 \text { min, } 28 \mathrm{~s} \text { on counselling, motivating and } \\
\text { offering a treatment plan. Patients who declared a desire to quit } \\
\text { smoking followed a treatment plan monitored by the doctor during } 3 \\
\text { in-person appointments and } 2 \text { telephone calls, and received a } \\
\text { stop-smoking guide. A D-day was established }\end{array}$ \\
\hline $\begin{array}{l}\text { Torrecilla et al } \\
(2001)^{38}\end{array}$ & $\mathrm{RCT}$ & $\begin{array}{l}304 \text { smokers older than } 18 \text { years recruited in } \\
\text { Salamanca (Spain) in } 1997\end{array}$ & $\begin{array}{l}\text { Presential visits } \\
\text { Written support } \\
\text { materials } \\
\text { Medication }\end{array}$ & $\begin{array}{l}\text { Patients with low nicotine dependence were randomised to two types } \\
\text { of intervention (doctor's counselling alone or within a 'minimal } \\
\text { intervention', conducted systematically). Patients with moderate-high } \\
\text { nicotine dependence received minimal intervention and NRT } \\
\text { (nicotine patch). Systematic minimal intervention (systematic } \\
\text { antismoking counselling at any opportunity during the office visit, } \\
\text { provision of written support materials that follow SEPAR } \\
\text { recommendations, psychological support and scheduled follow-up } \\
\text { visits to monitor the patient's process of breaking the habit. In the } \\
\text { minimal intervention group, follow-up visits were scheduled at } \\
15 \text { days and } 1,2,3,6 \text { and } 12 \text { months ( } 6 \text { visits). Transtheoretical } \\
\text { model of change was used. D-day was set. A third group within the } \\
\text { Ml group served as a control group }\end{array}$ \\
\hline $\begin{array}{l}\text { Twardella and } \\
\text { Brenner }(2007)^{32}\end{array}$ & $\begin{array}{l}\text { Clustered } \\
\mathrm{RCT}\end{array}$ & $\begin{array}{l}577 \text { smokers aged } 36-75 \text { years in Germany } \\
\text { in } 2002-2003\end{array}$ & $\begin{array}{l}\text { Presential visits } \\
\text { Professional } \\
\text { training } \\
\text { Financial } \\
\text { remuneration } \\
\text { Medication }\end{array}$ & $\begin{array}{l}\text { Control group: usual care } \\
\text { Intervention group } 1 \text { (training+incentive, TI): } 2 \mathrm{~h} \text { of training for } \\
\text { doctors on promoting smoking cessation (counselling, } \\
\text { transtheoretical model of change, medications) and financial } \\
\text { remuneration of the doctor for every patient who remains a } \\
\text { non-smoker at } 12 \text {-month follow-up }\end{array}$ \\
\hline
\end{tabular}


Reference (year Type of Study population Key elements of

of publication) study (inclusion criteria, study location) intervention

\section{Type of intervention}

Secades-Villa et al RCT $(2009)^{36}$
89 smokers aged 19-65 years in Asturias (Spain). Period NS
Ramos et al $(2010)^{37}$
RCT
Presential visits

Telephone calls Written support materials
Intervention group 2 (training+medication, TM): $2 \mathrm{~h}$ of training for doctors on promoting smoking cessation (counselling,

transtheoretical model of change, medications) and free medications (nicotine and/or bupropion) for their patients who want to quit. Intervention group 3: This group received $\mathrm{Tl}+\mathrm{TM}$

$\mathrm{TI}$ and $\mathrm{TM}$ group doctors received a free $2 \mathrm{~h}$ group training session, using a transtheoretical model of change. Groups of doctors were randomised to 3 study arms. No information about length of intervention or number of visits. No indication of D-day

Brief counselling: in about a 7 min session, the doctor provides brief counselling, informing about the negative effects of tobacco and the advantages of smoking cessation. The following recommendations are made: set a D-day, reduce cigarette consumption by one-third the week before D-day, carry out activities different from smoking a cigarette (physical exercise, handicrafts, etc). Hand out a brochure on the ' 6 reasons and 6 steps to stop smoking'

Self-help manual with telephone follow-up: carried out by the doctor and two primary care nurses. The intervention began with brief counselling (same as above) and distribution of 25-page multicomponent self-help manual covering the phases of preparation, cessation and maintenance (included the essential motivation messages, emphasising the advantages of smoking cessation, a weekly reduction in the number of cigarettes smoked, controlling the symptoms of withdrawal, identifying risk situations and preparing for D-day). Four follow-up telephone calls were made, in weeks $1,4,8$ and 12. In each call, the smoker verified his or her cessation status, whether he or she was practising the manual's recommendations, and was offered brief counselling

Intensive behavioural therapy: carried out by a clinical psychologist and based on the 5-week Becoña smoking cessation programme of a 20 min session each week. The programme includes information about the effects of tobacco, a contract in which the patient makes a commitment to stop smoking and to attend the weekly sessions, self-reporting and graphic representation of the cigarettes smoked, gradual reduction in the number of cigarettes smoked, social support for smoking abstinence, controlling the symptoms of withdrawal, biochemical feedback on cigarettes smoked (measurement of exhaled $\mathrm{CO}$ ) and strategies to avoid relapse

Professional Control group: MI. Health professionals received basic preparation and training 


\section{Panel A}

Reference (year Type of Study population Key elements of

$\begin{array}{llll}\text { of publication) } & \text { study } & \text { (inclusion criteria, study location) } & \text { intervention }\end{array}$

287 smokers older than 18 years with the Presential visits intention to quit smoking, in Mallorca (Spain) Group in 2005-2006

interventions Medication

\section{Type of intervention}

Cabezas et al

$(2011)^{30}$

Puente et al

$(2011)^{31}$

\section{Clustered}

RCT

2827 smokers aged 14-85 years, primary care patients in Spain in 2003-2005

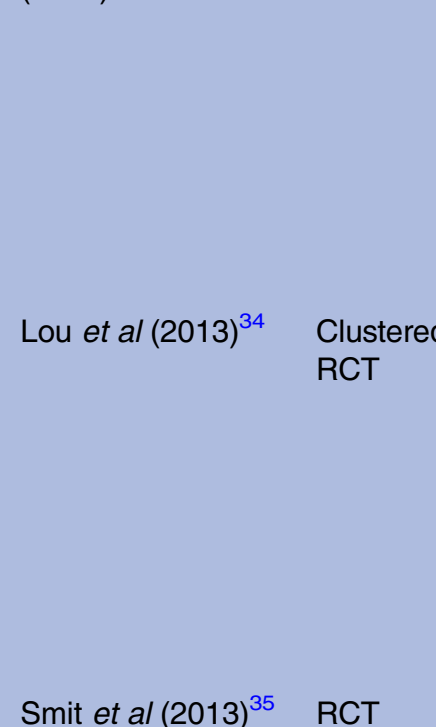

Smit et al (2013) $)^{35}$ RCT
3562 smokers with COPD in 14 primary care centres in the rural city of Xuzhou, China in 2008

414 smokers older than 18 years in the Netherlands, motivated to stop smoking within 6 months and with internet access in 2009-2010
Professional training Presential visits Medication

Presential visit Written materials

Presential visits Feedback letters Telephone calls

Intervention group I: III. Health professionals received prior training. Individual intervention consisted of 6 standardised weekly visits. The protocol recommended that the first visit last $20 \mathrm{~min}$ and the remainder $10 \mathrm{~min}$, although more time was actually spent Intervention group II: IGI. Health professionals received prior training. The IGI consisted of 6 standardised weekly visits lasting $60 \mathrm{~min}$ each, although in practice more time was spent

After the intervention, visits were scheduled after 1, 2, 3, 6, 9 and 12 months. The Prochaska model was used. NRT and bupropion were used at the doctor's discretion. A D-day was set

Control group: usual care

Intervention group: implementation of clinical practice guidelines recommendations during 6 months, including motivational interviews with smokers at the precontemplation-contemplation stage of change, a brief intervention with smokers in the preparation-action stage who do not want additional help, intensive intervention with pharmacological support for smokers in the preparation-action stage who want help, and reinforcement of the intervention with patients in the maintenance stage. The Prochaska model was used. A D-day was set. Medications were used at the doctor's discretion. A motivational intervention was used, and 6 office visits (intensive intervention). A $20 \mathrm{~h}$ training activity was provided before the trial All participants had an appointment with their doctor and the care team in the healthcare centre. Those who want to stop smoking receive a brochure indicating the toxic components in cigarettes, diseases related to smoking, benefits of smoking cessation, ways to stop smoking.

Control group: usual care

Intervention group: behavioural intervention and motivational interview

Two-year intervention. No pharmacological treatment provided during the study

Intervention group 1 (multiple tailoring): after setting a D-day to stop smoking, participants received 4 feedback letters: at the starting point, 2 days after D-day, after 6 weeks, and after 6 months. This feedback was personalised according to the characteristics of the participant. The feedback letters were 4-5 pages long and included 7 components: (1) introduction to the intention to stop smoking, (2) feedback related to the patient's attitude, (3) feedback related to the social influences surrounding tobacco, (4) feedback about how to

Continued 


of publication) study (inclusion criteria, study location) intervention

\section{Type of intervention}

handle situations that made him or her want to smoke, (5) feedback about actions that patients want to take to stop smoking, (6) feedback on how to handle situations where not smoking is difficult and (7) closing. Participants had access to the letters after they had completed an online questionnaire. It was also possible to send additional feedback letters by email

Intervention group 2 (multiple tailoring+counselling group): after receiving the first personalised letter, participants were prompted to schedule a visit with the nurse within the following 6-8 weeks for a personalised counselling session with a set protocol (instead of a third personalised letter). After 6 months, the nurse telephoned the patients to gather information about how they were progressing with smoking abstinence

Control group: usual care and recommendations

\section{Panel B}

\section{Reference (year}

of publication)

\section{Smoking abstinence}

3,6 and 12 months after D-day;

Daughton et al $(1998)^{33}$ confirmed by urine cotinine

\section{Main results}

Compared with placebo control group, intervention group participants showed greater abstinence at 3 months $(23.4 \%$ vs $11.4 \% ; p$ 0.01) and 6 months ( $18.5 \%$ vs $10.3 \% ; p$ 0.05). Abstinence at 1 year was $14.7 \%$ in the intervention group and $8.7 \%$ in the control group $(p=0.07)$

Grandes et al $(2000)^{29}$ $\mathrm{CO}$

6 and 12 months; confirmed by exhaled
The programme results were 5 percentage points higher in sustained abstinence at 1 year, with $7.1 \%$

Point prevalence abstinence achieved at 1 year after the MI was 39\% (29.4-49.3\%) and continuous abstinence was $30.9 \%$ (29.4-49.3\%) compared with $11 \%$ (5.6$18.8 \%$ ) point prevalence abstinence in the counselling-only group $(p<0.0001)$. In the NRT group, point prevalence abstinence was

\section{Author conclusions}

Use of the nicotine patch together with a brief intervention in primary care increased smoking cessation at 6 months. The duration of counselling, age of the patient, and the level of nicotine dependency may be important factors related to successful tobacco abstinence using nicotine patches for treatment

Programmes that combine counselling on how to stop smoking with the offer of support, follow-up, and the prescription of nicotine patches to those smokers who want to stop smoking are feasible and effective in daily clinical practice

Primary care is an ideal framework for antismoking interventions, using any of the established types of intervention: medical counselling only, systematic MI or specialised drug treatments using NRT; therefore, these types of intervention should
Continuous abstinence at 6 and 12 months; confirmed by exhaled $\mathrm{CO}$

Torrecilla
$(2001)^{38}$

(2)

Quality of the study*

Acceptable

\section{Acceptable}

Acceptable 


\section{Panel B \\ Reference (year}

of publication)

\section{Smoking abstinence}

Main results

$35.3 \%$ (24.1-47.8\%) and continuous

abstinence was $30.8 \%$

Twardella and

Brenner (2007) $)^{32}$

Continuous abstinence at 12 months

Smoking abstinence at 12 months was $3 \%$ in the control group, $3 \%$ in the intervention with an economic incentive for doctors, $12 \%$ when smokers were provided medications free of charge and $15 \%$ when both interventions were combined. The intervention with free medication had an OR to stop smoking was 4.77 ( $95 \% \mathrm{Cl} 2.03$ to 11.22)

Secades-Villa et al (2009) ${ }^{36}$

Ramos et al $(2010)^{37}$

Cabezas et al

$(2011)^{30}$

Puente et al

$(2011)^{31}$

Lou et al $(2013)^{34}$ confirmed by exhaled $\mathrm{CO}$
Continuous abstinence at 12 months confirmed by exhaled $\mathrm{CO}$

12 months; confirmed by exhaled $\mathrm{CO}$

At 12-month follow-up, intensive behavioural therapy (42.8\% abstinence) was more effective than a self-help programme $(27.5 \%)$ and the latter was superior to counselling $(12.9 \%)$. This pattern was also observed in continuous abstinence. Treatment adherence was higher in the intensive behavioural therapy group (82.8\% of all participants attended all therapy sessions) than in the self-help group $(61.8 \%$ completed the full programme)

Continuous abstinence at 12 months was $1 \%$ Intensive interventions were less effective in the control group, $7.4 \%$ in the III and $5.4 \%$ than expected

in the IGI. No statistical differences between individual and group interventions were observed. No differences were found between the intensive interventions and control group

12 and 24 months; confirmed by exhaled $\mathrm{CO}$

Continuous abstinence was $8.1 \%$ in the intervention group and $5.8 \%$ in the control group at 1 year $(p=0.014)$. The odds of smoking cessation in the intervention group compared with controls were $1.50(95 \% \mathrm{Cl}$ 1.05 to 2.14 )

24, 30 and 48 months postintervention;

Continuous abstinence was greater in members of the intervention group than control group between months 24 and 30 programmes in primary care

\section{Author conclusions}

Quality of

form part of routine daily activities in the primary care practice

Providing medications free of charge, along with short courses or specific training for healthcare professionals who care for those patients could lead to success in smoking cessation

Results confirm a dose-response effect in the treatment of smokers and indicate high

Acceptable acceptability of intensive behavioural

An intervention based on the transtheoretical model of change significantly increased abstinence at 2-year follow-up

Behavioural intervention doubled the smoking cessation results in patients with COPD

Acceptable 


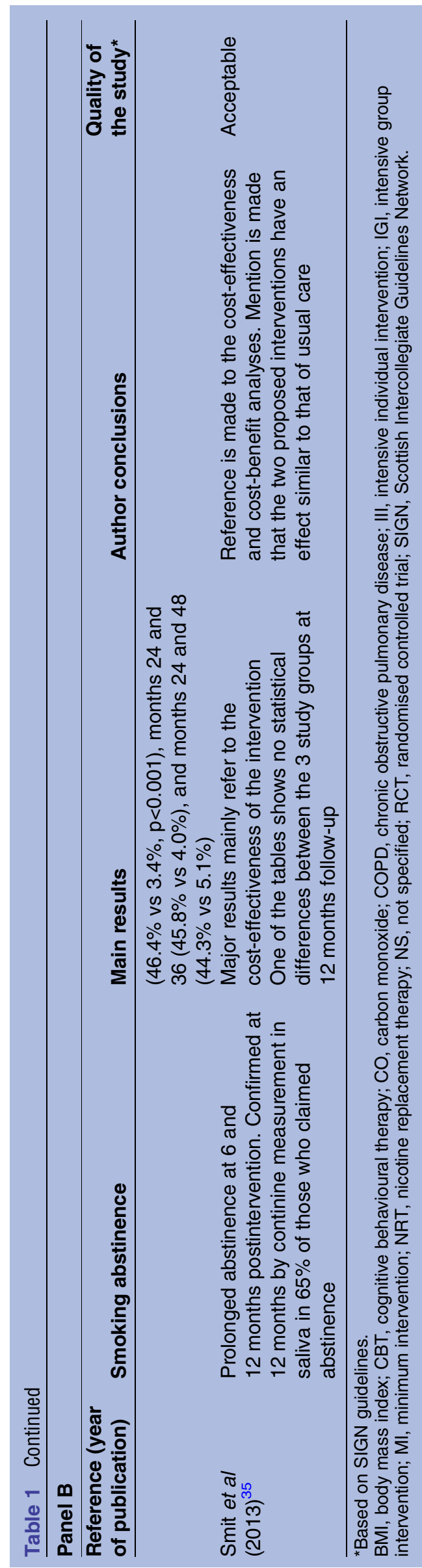

Components of the interventions

The studies based the multicomponent interventions for smoking cessation on the following components: raising awareness of the problem, education, motivation, behavioural change and medications. The methodologies used in the interventions were mainly individual or group sessions, telephone conversations, brochures or quit-smoking kits, and medications. Other approaches included economic incentives for doctors and no-cost medications for smokers, ${ }^{32}$ 'homework' assignments, and multifactor, community-based care.

In most studies, the control groups received usual primary care attention, including brief advice to stop smoking or an informational brochure about the harmful effects of tobacco on health. Only Daughton et $a l^{33}$ provided a placebo patch, worn for 10 weeks, and two primary care visits dealing with smoking cessation: their objective was to assess the effectiveness of the nicotine patch and they sought to ensure that the control group had the same characteristics. The study by Secades-Villa et $a l^{36}$ took a different approach, delivering some type of intervention in all three study arms.

Behavioural interventions were mainly mixed models based on clinical practice guidelines: behavioural therapy, the motivational interview proposed by Miller and Rollnich, ${ }^{39}$ and the transtheoretical model of change. ${ }^{40}$ Most of the Spanish trials reviewed ${ }^{30} 313738$ stand out for the following common characteristics: use of the model developed by Prochaska and Diclemente, advance training for participating health professionals, selection of a D-day to stop smoking and the use of medication at the discretion of the prescribing physician. In the study by Cabezas et al and Puente et al, a patient recruitment model adjusted to 'real-life' conditions and usual clinical practice was used, attracting patients from the general population who visited their health professionals spontaneously.

As can be seen in table 1 (specifically panel B) the majority of the included studies (seven out of nine) set a D-day for the patients to stop smoking.

\section{Effectiveness of multicomponent interventions Behavioural interventions}

Scaled interventions based on the transtheoretical model of change that included a motivational interview with smokers who visited a family doctor or nurse were associated with increased continuous tobacco abstinence at $1^{38}$ and 2 years of follow-up; ${ }^{30} 31$ gender was not a predictor of successful cessation. For instance, three studies using intensive interventions reported significant positive effects at 1 year: six visits with a healthcare professional achieved $8.1 \%$ continuous abstinence, compared with $5.8 \%$ in a control group; ${ }^{30}$ a comparison of an individual intervention, group intervention and control group observed abstinence rates of $7.4 \%, 5.4 \%$ and $1 \%$, respectively; ${ }^{37}$ and a complex intervention achieved $30.8 \%$ continuous abstinence compared with $11 \%$ in the control group. ${ }^{38}$ Twardella and Brenner did not obtain 


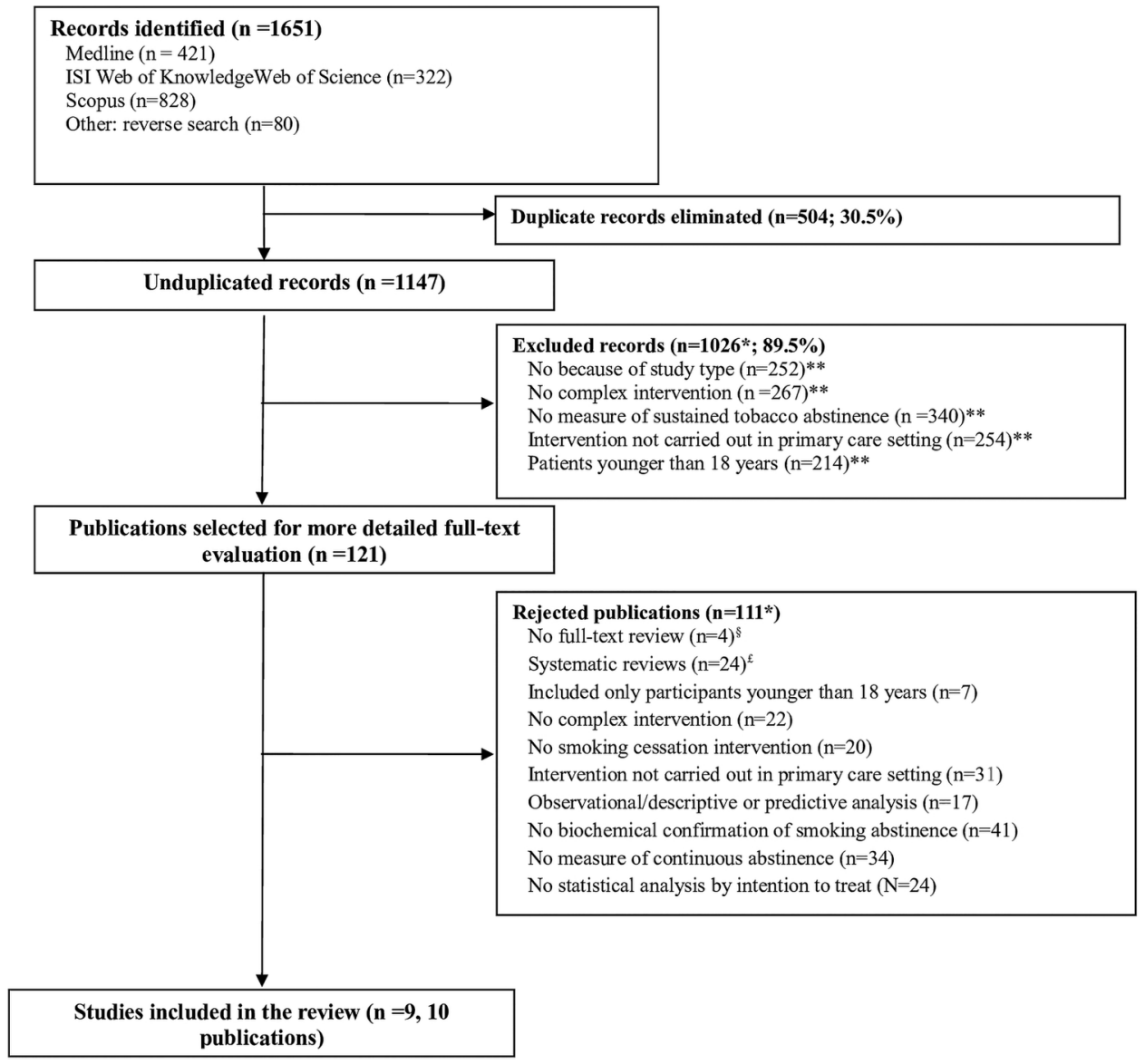

Figure 1 Flow chart of article selection for the study.

better cessation rates than controls $(3 \%)$ when doctors provided an intervention based on counselling and the transtheoretical model of change, but did see improvement $(12 \%)$ when free prescription medications were provided for patients. ${ }^{32}$ The intervention proposed by Smit $e$ t $a \hat{l}^{35}$ combined two methodologies: Internet feedback messages and meetings with nurses based on the I-Change Model (ICM) supported by Prochaska's theories did not produce significant results.

The 2-year behavioural intervention proposed by Lou et al in patients with chronic obstructive pulmonary disease who smoke is based on a motivational interview. Their study obtained an abstinence rate of $46.4 \%$ (control group: $3.4 \%$ ) at 24 and 30 months postintervention. ${ }^{34}$

Intensive behavioural therapy based on a 5-week smoking cessation programme consisting of $20 \mathrm{~min}$ weekly sessions obtained continuous abstinence of $42.8 \%$ at 12 months, compared with $12.9 \%$ for brief counselling. ${ }^{41}$ This programme included information about the effects of smoking, a contract in which the patient makes a commitment to stop smoking and attend the weekly sessions, self-recording and graphic representation of cigarettes smoked, gradual reduction in the number of cigarettes smoked, social support for abstinence, controlling the symptoms of tobacco withdrawal, biochemical feedback on cigarettes smoked (measurement of exhaled $\mathrm{CO}$ ) and strategies to prevent relapse. $^{36}$

In the studies that analysed treatment efficacy based on intensity or complexity, the observation was that the more components the intervention had, the more follow-ups the professional provided, and the more individualised these were, the better were the results in terms of continuous abstinence from smoking. In the study by Secades-Villa $e t a l,{ }^{36}$ the least intensive intervention, a self-help manual with a follow-up telephone call, obtained lower rates of continuous abstinence at 12 months than the most intensive intervention arm, but more than twice the rates achieved by patients who received only brief counselling $(27.5 \%, 42.8 \%$ and $12.9 \%$, respectively). Although lower than expected, Ramos et al observed non-significantly higher rates of continuous abstinence at 12 months from intensive interventions $(7.4 \%$ in the individual and $5.4 \%$ in the group sessions), compared with the control group $(1 \%)$. The authors point out that this effect could be explained by the initial participant characteristics: they more strictly selected smokers for the intensive interventions in primary care, and the health professionals provided few prescriptions for drug therapies. ${ }^{37}$

The study by Twardella and Brenner ${ }^{32}$ demonstrated greater effectiveness in smoking cessation in the 
Table 2 Quality of the randomised clinical trials included in the review, based on SIGN guidelines (continued on following page)

\begin{tabular}{|c|c|c|c|c|c|}
\hline Ítem & Daughton et al (1998) & $\begin{array}{l}\text { Grandes et al } \\
(2000)\end{array}$ & $\begin{array}{l}\text { Torrecilla } \\
\text { et al (2001) }\end{array}$ & $\begin{array}{l}\text { Twardella et al } \\
(2007)\end{array}$ & $\begin{array}{l}\text { Secades-Villa } \\
\text { et al (2009) }\end{array}$ \\
\hline $\begin{array}{l}\text { 1. The study addresses an appropriate and clearly focused } \\
\text { question? }\end{array}$ & Yes & Yes & Yes & Yes & Yes \\
\hline $\begin{array}{l}\text { 2. The assignment of participants to treatment groups is } \\
\text { randomised? }\end{array}$ & Yes & No & Yes & Yes & Yes \\
\hline 3. An adequate concealment method is used & Yes & Yes & Can't say & Can't say & Can't say \\
\hline $\begin{array}{l}\text { 4. Participants and investigators are kept 'blind' about treatment } \\
\text { allocation }\end{array}$ & Yes & No & Can't say & No & Can't say \\
\hline $\begin{array}{l}\text { 5. The treatment and control groups are similar at the start of the } \\
\text { trial }\end{array}$ & Yes & Yes & Yes & Yes & No \\
\hline $\begin{array}{l}\text { 6. The only difference between groups is the treatment under } \\
\text { investigation }\end{array}$ & Yes & Yes & Yes & Yes & Yes \\
\hline $\begin{array}{l}\text { 7. All relevant outcomes are measured in a standard, valid and } \\
\text { reliable way }\end{array}$ & Yes & Yes & Yes & Yes & Yes \\
\hline $\begin{array}{l}\text { 8. What percentage of the individuals or clusters recruited into } \\
\text { each treatment arm of the study dropped out before the study } \\
\text { was completed? }\end{array}$ & $\begin{array}{l}1.1 \% \text { at } 3 \text { months, } 1.6 \text { at } \\
6 \text { months and } 2.2 \% \text { at } \\
1 \text { year }\end{array}$ & $\begin{array}{l}\text { Control group: } \\
1.8 \% \\
\text { Intervention } \\
\text { group: } 4.6 \%\end{array}$ & $\begin{array}{l}\text { CG: } 6 \% \\
\text { Isolated } \\
\text { advice : } 3 \% \\
\text { NRT: } 7.7 \%\end{array}$ & $\begin{array}{l}\text { CG: } 19 \% \\
\text { The interventions } \\
14-17 \%\end{array}$ & $1.2 \%$ \\
\hline $\begin{array}{l}\text { 9. All the participants are analysed in the groups to which they } \\
\text { were randomly allocated (often referred to as intention-to-treat } \\
\text { analysis) }\end{array}$ & Yes & Yes & Yes & Yes & Yes \\
\hline $\begin{array}{l}\text { 10. Where the study is carried out at more than one site, results } \\
\text { are comparable for all sites }\end{array}$ & Yes & Yes & $\begin{array}{l}\text { Does not } \\
\text { apply }\end{array}$ & Yes & Does not apply \\
\hline 11. How well was the study done to minimise bias? & Acceptable & Acceptable & Acceptable & Acceptable & Acceptable \\
\hline $\begin{array}{l}\text { 12. Taking into account clinical considerations, your evaluation of } \\
\text { the methodology used, and the statistical power of the study, } \\
\text { are you certain that the overall effect is due to the study } \\
\text { intervention? }\end{array}$ & Yes & Yes & Yes & Yes & Yes \\
\hline
\end{tabular}

\begin{tabular}{|c|c|c|c|c|}
\hline Ítem & $\begin{array}{l}\text { Ramos et al } \\
(2010)\end{array}$ & $\begin{array}{l}\text { Cabezas et al and } \\
\text { Puente et al (2011) }\end{array}$ & Lou et al (2013) & Smit et al (2013) \\
\hline 1. The study addresses an appropriate and clearly focused question? & Yes & Yes & Yes & Yes \\
\hline 2. The assignment of participants to treatment groups is randomised? & Yes & Yes & Yes & Not clear \\
\hline 3. An adequate concealment method is used & Yes & Yes & No & Yes \\
\hline $\begin{array}{l}\text { 4. Participants and investigators are kept 'blind' about treatment } \\
\text { allocation }\end{array}$ & Yes & No & No & No \\
\hline 5. The treatment and control groups are similar at the start of the trial & Yes & Yes & Yes & Yes \\
\hline $\begin{array}{l}\text { 6. The only difference between groups is the treatment under } \\
\text { investigation }\end{array}$ & Yes & Yes & Yes & Can't say \\
\hline
\end{tabular}

investigation 


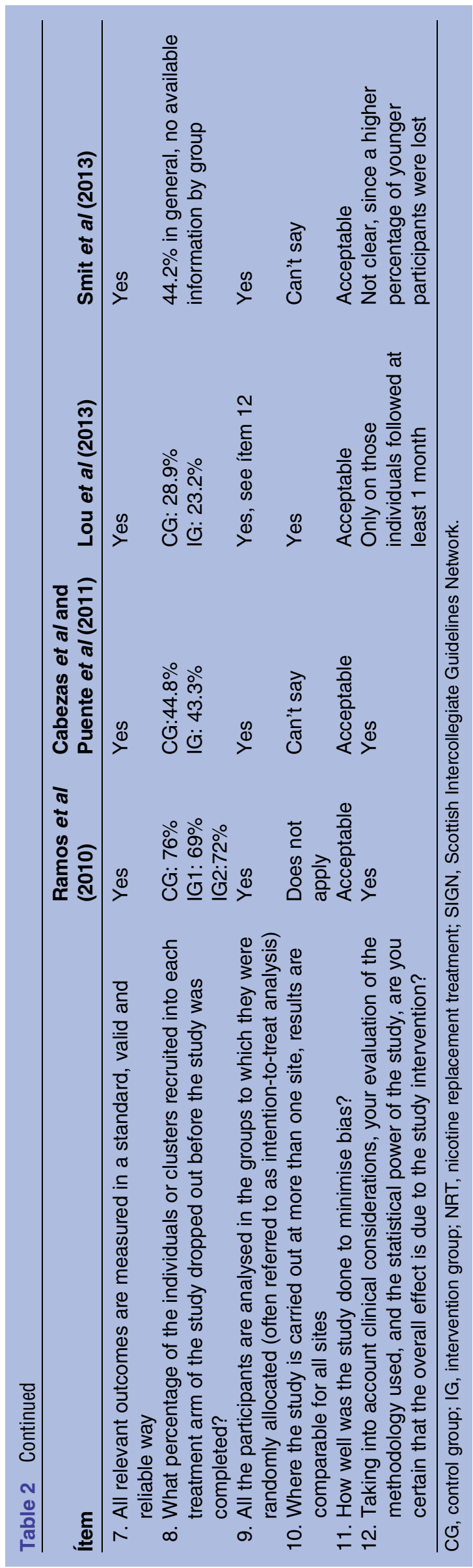

presence of symptomatology or previous diseases related to smoking and older age, but an economic incentive for health professionals was not effective. On the other hand, Lou $e t a l^{34}$ found a relationship between effectiveness and a non-smoking family environment and a family doctor and nurse who were not smokers.

According to some studies, specific training for healthcare professionals who care for smokers who want to stop smoking may increase their probability of success. ${ }^{29} 32$ Twardella and Brenner ${ }^{32}$ point out that other studies had previously shown training programmes to have beneficial effects on the number of smokers identified and offered advice and support for quitting. However, the effect of the increased efforts on smoking cessation could not be proved.

Finally, in primary care-as has occurred in other settings-a dose-response effect has been observed in the interventions, with greater abstinence as more interventions are provided. In addition, intensive interventions typically have high rates of acceptance in the primary care setting. ${ }^{36}$

\section{Pharmacological interventions}

The pharmacological interventions identified include two classes of drugs that are effective in smoking cessation: nicotine replacement therapy (NRT) and bupropion. This review did not include any studies of complex interventions that included varenicline use in primary care.

The use of nicotine patches along with a brief intervention, compared with a group that received placebo patches, increased continuous tobacco abstinence at 6 months $(18.5 \%$ vs $10.3 \%)$ and 12 months $(14.7 \%$ vs $8.7 \%){ }^{33}$ In another study, continuous abstinence in patients with moderate-high nicotine dependence who used NRT was $30.8 \%$ at 1 year, compared with $11 \%$ in the group that received only the doctor's advice. ${ }^{38}$

Although we excluded some studies from the review for their lack of biochemical confirmation, ${ }^{42-44}$ they offer several contributions to this discussion: One study showed that the length of the counselling, ${ }^{44}$ in addition to the age of the patient and nicotine dependency, ${ }^{33}$ are important factors related to the success of smoking abstinence, and providing treatment to break the smoking habit free of charge can increase the probability of success. ${ }^{32}$ Therefore, programmes delivered in routine daily practice in the primary care setting that combine counselling, offers of assistance, follow-up and prescriptions for treatments that specifically help to break the smoking habit are feasible, effective ${ }^{29}$ and safe $^{43}$; furthermore, these complex interventions are more effective than minimal counselling. ${ }^{42} 43$ The combined use in primary care of bupropion, NRT, cognitive behavioural therapy and minimal intervention is feasible, safe and achieves results ranging from $20 \%$ to $29.6 \%$ of continuous abstinence at 12 months, with no differences between them but an advantage over counselling alone; the only obstacle is adherence to treatment. $^{43}$ 
In the absence of a standard drug therapy in all studies and of any comparison of different medications and doses, it was impossible to analyse a specific effect for each drug prescribed at the discretion of the attending physician as a complement to some of the interventions reviewed. We assumed that medications were prescribed in accordance with current guidelines but were unable to analyse their effects on patient outcomes.

\section{Follow-up}

One of the main inclusion criteria for publications to be reviewed was at least 6 months of postintervention follow-up. This was because shorter time intervals carry a very high probability of relapse and abstinence is not considered definitive until at least 6 months have passed without smoking. Therefore, the included interventions had a follow-up of 6 months or more. Most of the publications reported follow-up of 6 or 12 months. Cabezas et $a l^{30}$ and Puente et $a l^{31}$ also conducted a 2-year follow-up, and Lou et $a l^{34}$ reported on the longest follow-up, reaching a maximum of 5 years.

\section{DISCUSSION}

The objective of the present review was to summarise on the effectiveness of multicomponent interventions with respect to continuous abstinence from tobacco. We included both randomised and non-randomised clinical trials involving smokers older than 18 years and attended in the primary care setting that assess continuous abstinence (at least 6 months) and include biochemical confirmation. Nine studies, eight RCTs and one non-RCT with these characteristics were identified.

In the present review, we found that the multicomponent interventions included increased abstinence in the long term, achieving continuous abstinence after 1 year from about $7 \%$ to just over $40 \%$ in comparison with control groups (usual care). This wide range of percentages can be attributed to differences in patient selection criteria. Owing to the heterogeneity and differences in intensity of the interventions included, it can be complicated to determine the duration and type of intervention that is most effective in achieving better rates of continued abstinences. In general, we observed that with more components, more follow-ups by the health professional and more intense interventions, better smoking abstinence results were achieved. In addition, multicomponent strategies were more effective when medications were used and a 'D-day' was set.

Biochemical confirmation, measuring either exhaled $\mathrm{CO}$ or cotinine in urine or saliva, provides researchers with a far more rigorous assessment than a patient's selfreport of continuous smoking cessation, as does longterm follow-up. Unfortunately, four studies reported more than 20\% loss to follow-up. ${ }^{30} 31343537$

The published literature has observed that brief counselling in the healthcare setting increases the frequency of efforts to stop smoking. The systematic review by
Aveyard et $a t^{45}$ found a risk ratio (RR) of 1.24 (95\% CI 1.16 to 1.33) for brief counselling, less than that of behavioural support ( $\mathrm{RR}=2.17 ; 95 \%$ CI 1.52 to 3.11 ) or NRT (RR=1.68; 95\% CI 1.48 to 1.89). The effect of brief counselling on the rates of smoking cessation seems to be small; in a 2008 systematic review, Stead and colleagues found that brief counselling increased these rates only 1-3\% compared with attempts made without medical assistance. More intensive interventions also contributed a benefit, although scant. A doctor's advice helps smokers to stop smoking, even if it is brief counselling. It appears that the intensity and follow-up can achieve higher rates of cessation. ${ }^{13}$ Individual counselling is frequently used to help patients stop smoking, but there is insufficient evidence to establish whether higher intensity counselling is more effective. ${ }^{46}$ The effectiveness of drug therapies is more clear: a review by $\mathrm{Wu}$ et $a l^{47}$ found that NRT, bupropion and varenicline are effective complementary methods of smoking cessation.

Our data concur in large part with an earlier review, ${ }^{14}$ which reported that the effectiveness of multiple/ complex interventions in achieving sustained smoking cessation in adult primary care patients had an OR of 2.2 (95\% CI 1.7 to 2.8), compared with a control group. The same authors found differences between the effect of brief counselling and intensive counselling with a multicomponent intervention (OR 1.37, 95\% CI 1.20 to 1.56) and also when medications were used to help the smoker (OR 3.45, 95\% CI 2.8 to 4.2).

With respect to intervention models, various trials analysed for this review used the transtheoretical model of change with positive results; however, reviews of literature have not arrived at a clear conclusion about the effectiveness of this model. ${ }^{48-50}$ Although the objective of the present review was not to specifically evaluate this model, the clinical trials indicate that it is well accepted by health professionals and the study populations.

On the other hand, the Cochrane review by Stead and Lancaster ${ }^{15}$ points out that, without any doubt, the combination of behavioural strategies with drug therapies has been shown to be clearly useful, which is in accordance with the data reported in this review.

Therefore, usual clinical practice should include interventions with more than one component, adapting the characteristics of the intervention to the type of service offered, and time and training of healthcare personnel is necessary to achieve a useful strategy. With respect to the research, more studies must be designed to clarify the combination of behavioural strategies and use of medications that is most effective in usual practice in specific population groups, and the cost-effectiveness of those combinations.

\section{Limitations}

One of the major limitations of the present review, and of all reviews in general, is the publication bias that in this case we attempted to control by searching for data 
in the STAN Bulletin, which publishes all types of news items and other information. Furthermore, it was not possible to include references from presentations at conferences and meetings, although we believe that the work with the greatest potential importance has been published in journals with an impact factor. We have only included those studies published in English or Spanish. Another limitation of this study, despite the rather strict inclusion criteria, is that the age of the participants, the populations studied, and the type and duration of the interventions and follow-up contributed to the heterogeneity of the results. In clinical trials, the most frequently recommended measurement of continuous smoking cessation is 'continuous abstinence', defined as no use of any amount of tobacco from the day the individual stops smoking until the day data are analysed. This definition has also been called 'sustained abstinence' and 'prolonged abstinence'.27 The Cochrane Tobacco Addiction Group also references other types of abstinence: 'point prevalence abstinence' for short periods without smoking and 'prolonged abstinence', which is similar to 'continuous abstinence' and analyses abstinence after a grace period of about 2 weeks. ${ }^{51}$ In order to strengthen the reliability of the results, we decided to follow the recommendations by West $e t a l^{2}$ and of the Society for Research on Nicotine and Tobacco Europe ${ }^{53}$ where they propose to undertake a biochemical verification to confirm smoking cessation. However, we may have incurred into some selection bias due to the fact that we have only included studies with biochemical verification of smoking cessation.

Another possible bias in this review is the loss to follow-up; three of the studies reported more than $40 \%$ loss to follow-up (one of them reported a $76 \%$ loss). In order to limit this bias and to ensure a certain level of quality, we included only trials that used an ITT approach. In addition, we must take into account the increased motivation to stop smoking that is normally present in smokers who agree to participate in clinical trials. This review likely underestimated the effectiveness of some of the multicomponent interventions: In many RCTs, the control group is offered brief counselling by healthcare professionals, which in and of itself increases smoking cessation. Another limitation of the included studies is the lack of blinded interventions, but it is important to remember that the very nature of the behavioural interventions in many cases impede efforts to achieve a blind intervention.

The search ended in February 2014 and it might be quite old, the analysis and subsequent steps took us longer than expected. However, we believe that the number of publications will have not changed and results will have not changed significantly.

Our search strategy included the term 'complex intervention'; consequently, we reviewed those articles that mentioned the terms 'complex' or 'multiple' in their title or abstract. This search strategy brought us to select nine trials, mainly conducted in Spain and in somewhat low impact factor journals. Maybe the research question is a topic of concern in the Spanish primary care community. Besides, there is not a clear consensus on what it is a 'complex intervention'. Consequently, we may have omitted the analysis of some of the components that define an intervention as a complex one, such as the participation of some disciplines, changes in the environment or the effect of different professionals. All these aspects could be clarified in future reviews, but most studies do not offer this information on their publications.

\section{Study implications}

Future studies of complex interventions to achieve smoking cessation should use standardised methods to evaluate outcomes, as proposed by Hughes et $a l^{27}$ On the other hand, as complex interventions are involved, interventions based on clinical practice guidelines must be standardised to incorporate the key elements of those guidelines, basically focused on behavioural and pharmacological elements. We therefore, believe that clinical practice guideline should recommend interventions with two or more components. Another recommendation is that the studies should analyse cost-effectiveness.

On the other hand, the majority of the interventions were carried out in European populations (mostly in Spain), two studies in the USA population ${ }^{33}$ and one in China. ${ }^{34}$ Consequently, it is not clear whether the findings are applicable to other populations, and we believe it is necessary to develop this type of interventions and evaluate their effectiveness in other populations.

\section{CONCLUSIONS}

Very few studies have evaluated complex/multicomponent interventions in the primary care setting that are designed to promote smoking cessation, even though this approach is useful, effective, safe, and achieves greater long-term continuous cessation (between $7 \%$ and $40 \%$ ) than usual care and counselling alone (which also is effective). Behavioural interventions are effective and have a dose-response effect. In fact, the more support the smoker receives-more components, more follow-up by the health professional, longer durationand the more personalised is the intervention, the greater the continuous smoking cessation achieved. Nonetheless, no differences were observed between the different types of intervention. The multicomponent strategies are more effective when the smoker sets a 'D-day' and medications are prescribed. The drugs used in the studies analysed (NRT and bupropion) are useful, safe and effective, with no differences observed between them. The use of other strategies such as providing patients with free medication can increase the success of these treatments. Therefore, a complex intervention to help smokers quit should include: several monitoring visits, longer periods to follow-up patients, behavioural 
components and possibility to set a 'D-day' and prescribe medication. Despite the evidence that multicomponent interventions are effective, it is not clear which of the components of the different interventions are key. Further research is needed to determine which combinations are most efficient.

\section{Author affiliations}

${ }^{1}$ Unitat de Suport a la Recerca Barcelona, Institut Universitari d'Investigació en Atenció Primària Jordi Gol (IDIAP Jordi Gol), Barcelona, Spain

${ }^{2}$ Centre d'Atenció Primària (CAP) Passeig de Sant Joan, Institut Català de la Salut (ICS), Barcelona, Spain

${ }^{3}$ Department of Medicine, Universitat Autònoma de Barcelona, Barcelona, Spain

${ }^{4}$ Centre d'Atenció Primària (CAP) Florida Nord, Institut Català de la Salut (ICS), Hospitalet de Llobregat, Barcelona, Spain

${ }^{5}$ Centro de Salud Santo Grial, Huesca, Spain

${ }^{6}$ Centre d'Atenció Primària (CAP) Sant Antoni, Institut Català de la Salut (ICS), Barcelona, Spain

${ }^{7}$ Centre d'Atenció Primària (CAP) La Garriga, Institut Català de la Salut (ICS), La Garriga, Barcelona, Spain

${ }^{8}$ Unitat de Suport a la Recerca Metropolitana Nord, Institut Universitari d'Investigació en Atenció Primària Jordi Gol (IDIAP Jordi Gol), Sabadell, Spain

${ }^{9}$ Centre d'Atenció Primària (CAP) La Llagosta, Institut Català de la Salut (ICS), La Llagosta, Spain

${ }^{10}$ Centre d'Atenció Primària (CAP) la Sagrera, Institut Català de la Salut (ICS), Barcelona, Spain

${ }^{11}$ Centre d'Atenció Primària (CAP) Esplugues de Llobregat, Institut Català de la Salut (ICS), Esplugues de Llobregat, Spain

Acknowledgements The authors thank Marta Jordan, Medicine Library, Universitat Autònoma de Barcelona, for her assistance with the search strategy; Enriqueta Pujol Ribera, researcher of the Institut Universitari d'Investigació en Atenció Primària (IDIAP) Jordi Gol, for her comments on the manuscript and in the process of selecting articles during the revision; and Edurne Zabaleta, IDIAP Jordi Gol researcher, for her comments and her assistance with manuscript preparation and submission, supported by Elaine Lilly (Writer's First Aid). They also thank IDIAP Jordi Gol for the institute's support for the study.

Contributors CMC planned the study. CMC and EP performed the searches, screened articles in duplicate, abstracted the data and drafted the manuscript. All authors performed critical analysis of abstracts and main text and assisted with any unresolved disagreements. All authors were involved in developing the study. All authors read and approved the final manuscript.

Funding The project has received funding from a Network for Prevention and Health Promotion in Primary Care (redIAPP, RD12/0005) grant and a research project grant (PI12/01914) from the Instituto de Salud Carlos III (Institute of Health Carlos III) of the Ministry of Economy and Competitiveness (Spain), co-financed with European Union ERDF funds.

Competing interests None declared.

Provenance and peer review Not commissioned; externally peer reviewed.

Data sharing statement No additional data are available.

Open Access This is an Open Access article distributed in accordance with the Creative Commons Attribution Non Commercial (CC BY-NC 4.0) license, which permits others to distribute, remix, adapt, build upon this work noncommercially, and license their derivative works on different terms, provided the original work is properly cited and the use is non-commercial. See: http:// creativecommons.org/licenses/by-nc/4.0/

\section{REFERENCES}

1. World Health Organization. WHO global report on mortality attributable to tobacco. 2012. http://apps.who.int/iris/bitstream/10665/ 44815/1/9789241564434_eng.pdf
2. Gaziano TA, Galea G, Reddy KS. Chronic diseases 2-scaling up interventions for chronic disease prevention: the evidence. Lancet 2007;370:1939-46.

3. Kahn R, Robertson RM, Smith R, et al. The impact of prevention on reducing the burden of cardiovascular disease. Circulation 2008;118:576-85.

4. Benowitz NL. Cigarette smoking and cardiovascular disease: pathophysiology and implications for treatment. Prog Cardiovasc Dis 2003;46:91-111.

5. Fiore MC, Jaen CR, Baker TB, et al. Treating tobacco use and dependence: 2008 update US Public Health Service Clinical Practice Guideline executive summary. Respir Care 2008;53:1217-22. http://bphc.hrsa.gov/buckets/treatingtobacco.pdf (accessed 11 Dec 2014).

6. Tengs TO, Adams ME, Pliskin JS, et al. Five-hundred life-saving interventions and their cost-effectiveness. Risk Anal 1995;15:369-90.

7. Eckert T, Junker C. Motivation for smoking cessation: what role do doctors play? Swiss Med Wkly 2001;131:521-6.

8. Kreuter MW, Chheda SG, Bull FC. How does physician advice influence patient behavior? Evidence for a priming effect. Arch Fam Med 2000;9:426-33.

9. Ossip-Klein DJ, Mclntosh S, Utman C, et al. Smokers ages 50+: who gets physician advice to quit? Prev Med 2000;31:364-9.

10. Stead LF, Buitrago D, Preciado N, et al. Physician advice for smoking cessation. Cochrane Database Syst Rev 2013;5: CD000165.

11. Russell MA, Wilson $\mathrm{C}$, Taylor $\mathrm{C}$, et al. Effect of general practitioners advice against smoking. BMJ 1979;2:231-5.

12. Lemmens V, Oenema A, Knut IK, et al. Effectiveness of smoking cessation interventions among adults: a systematic review of reviews. Eur J Cancer Prev 2008;17:535-44.

13. Stead LF, Bergson G, Lancaster T. Physician advice for smoking cessation. Cochrane Database Syst Rev 2008;(2):CD000165.

14. Papadakis S, McDonald P, Mullen KA, et al. Strategies to increase the delivery of smoking cessation treatments in primary care settings: a systematic review and meta-analysis. Prev Med 2010;51:199-213.

15. Stead LF, Lancaster T. Combined pharmacotherapy and behavioural interventions for smoking cessation. Cochrane Database Syst Rev 2012;10:CD008286

16. Craig P, Dieppe P, Macintyre S, et al. Developing and evaluating complex interventions: the new Medical Research Council guidance. BMJ 2008;337:a1655.

17. Craig $\mathrm{P}$, Dieppe $\mathrm{P}$, Macintyre $\mathrm{S}$, et al. Developing and evaluating complex interventions: the new Medical Research Council guidance. Int J Nurs Stud 2013;50:587-92.

18. Petticrew $\mathrm{M}$, Anderson $\mathrm{L}$, Elder $\mathrm{R}$, et al. Complex interventions and their implications for systematic reviews: a pragmatic approach. $J$ Clin Epidemiol 2013;66:1209-14.

19. Dwamena F, Holmes-Rovner M, Gaulden CM, et al. Interventions for providers to promote a patient-centred approach in clinical consultations. Cochrane Database Syst Rev 2012;12:CD003267.

20. Grandes G, Sanchez A, Cortada JM, et al. Is integration of healthy lifestyle promotion into primary care feasible? Discussion and consensus sessions between clinicians and researchers. BMC Health Serv Res 2008;8:213.

21. Lau R, Stevenson F, Ong BN, et al. Addressing the evidence to practice gap for complex interventions in primary care: a systematic review of reviews protocol. BMJ Open 2014;4:e005548.

22. Wong $G$, Greenhalgh $T$, Westhorp $G$, et al. RAMESES publication standards: realist syntheses. J Adv Nurs 2013;69:1005-22.

23. Guise JM, Chang C, Viswanathan M, et al. Systematic reviews of complex multicomponent health care interventions. Research White Paper. AHRQ Publication No. 14-EHC003-EF. Rockville, MD. Agency for Research and quality, 2014. http://effectivehealthcare.ahrq.gov/ index.cfm/search-for-guides-reviews-and-reports/?productid=1878 \&pageaction=displayproduct. (accessed $11 \mathrm{Dec} 2014$ ).

24. Jaakkimainen L, Schultz S, Klein-Geltink J, et al. Ambulatory physician care for adults. In: Jaakkimainen L, Upshur R, Klein-Geltink J, Leong A, Maaten S, Schultz S, Wang L, eds. Primary care in Ontario: ICES Atlas. Toronto: Institute for Clinical Evaluative Sciences, 2006:53-76.

25. Zwar NA, Richmond RL. Role of the general practitioner in smoking cessation. Drug Alcohol Rev 2006;25:21-6.

26. Moher D, Liberati A, Tetzlaff $\mathrm{J}$, et al. Preferred reporting items for systematic reviews and meta-analyses: the PRISMA statement. Ann Intern Med 2009;151:264-9, W64.

27. Hughes JR, Keely JP, Niaura RS, et al. Measures of abstinence in clinical trials: issues and recommendations. Nicotine Tob Res 2003;5:13-25. 
28. Shatenstein S. Smoking \& Tobacco Abstracts \& News (STAN Bulletin). 2014

29. Grandes G, Cortada JM, Arrazola A. An evidence-based programme for smoking cessation: effectiveness in routine general practice. $\mathrm{Br} \mathrm{J}$ Gen Pract 2000;50:803-7.

30. Cabezas C, Advani M, Puente D, et al. Effectiveness of a stepped primary care smoking cessation intervention: cluster randomized clinical trial (ISTAPS study). Addiction 2011;106:1696-706.

31. Puente D, Cabezas C, Rodriguez-Blanco T, et al., ISTAPS study group investigators. The role of gender in a smoking cessation intervention: a cluster randomized clinical trial. BMC Public Health 2011;11:369.

32. Twardella $\mathrm{D}$, Brenner $\mathrm{H}$. Effects of practitioner education, practitioner payment and reimbursement of patients' drug costs on smoking cessation in primary care: a cluster randomised trial. Tob Control 2007;16:15-21.

33. Daughton D, Susman J, Sitorius M, et al. Transdermal nicotine therapy and primary care. Importance of counseling, demographic, and participant selection factors on 1-year quit rates. The Nebraska Primary Practice Smoking Cessation Trial Group. Arch Fam Med 1998;7:425-30.

34. Lou PA, Zhu YA, Chen PP, et al. Supporting smoking cessation in chronic obstructive pulmonary disease with behavioral intervention: a randomized controlled trial. BMC Fam Pract 2013;14:91.

35. Smit ES, Evers SM, de Vries $\mathrm{H}$, et al. Cost-effectiveness and cost-utility of internet-based computer tailoring for smoking cessation. J Med Internet Res 2013;15:e57.

36. Secades-Villa R, Alonso-Perez F, Garcia-Rodriguez O, et al. Effectiveness of three intensities of smoking cessation treatment in primary care. Psychol Rep 2009;105:747-58.

37. Ramos M, Ripoll J, Estrades T, et al. Effectiveness of intensive group and individual interventions for smoking cessation in primary health care settings: a randomized trial. BMC Public Health 2010;10:89.

38. Torrecilla García M, Barrueco Ferrero M, Maderuelo Fernández J, et al. [Tobacco detoxication at a primary care clinic: efficacy of medical counseling, minimal intervention and nicotine replacement therapy at the one-year follow-up]. Aten Primaria 2001;27:629-36.

39. Miller WR, Rollnick S. Motivational interviewing. New York: Preparing people for change Guilford, 2002.

40. Prochaska JO, DiClemente CC. The transtheoretical approach. Handb Psychother Integr 2005;2:147-71.
41. Becoña E, Vázquez FL. Does using relapse prevention increase the efficacy of a program for smoking cessation? An empirical study. Psychol Rep 1997;81:291-6.

42. Cene CW, Yanek LR, Moy TE, et al. Sustainability of a multiple risk factor intervention on cardiovascular disease in high-risk African American families. Ethn Dis 2008;18:169-75.

43. Wittchen HU, Hoch $\mathrm{E}$, Klotsche J, et al. Smoking cessation in primary care-a randomized controlled trial of bupropione, nicotine replacements, CBT and a minimal intervention. Int $J$ Methods Psychiatr Res 2011;20:28-39.

44. Zhu SH, Stretch V, Balabanis M, et al. Telephone counseling for smoking cessation: effects of single-session and multiple-session interventions. J Consult Clin Psychol 1996;64:202-11.

45. Aveyard P, Begh R, Parsons A, et al. Brief opportunistic smoking cessation interventions: a systematic review and meta-analysis to compare advice to quit and offer of assistance. Addiction 2012;107:1066-73.

46. Lancaster T, Stead LF. Individual behavioural counselling for smoking cessation. Cochrane Database Syst Rev 2005;(2): CD001292.

47. Wu $\mathrm{P}$, Wilson $\mathrm{K}$, Dimoulas $\mathrm{P}$, et al. Effectiveness of smoking cessation therapies: a systematic review and meta-analysis. BMC Public Health 2006:6:300.

48. Andersen S, Keller C, McGowan N. Smoking cessation: the state of the science. The utility of the transtheoretical model in guiding interventions in smoking cessation. Online J Knowl Synth Nurs 1999;6:9.

49. Cahill K, Lancaster T, Green N. Stage-based interventions for smoking cessation. Cochrane Database Syst Rev. 2010;10:CD004492.

50. Riemsma RP, Pattenden J, Bridle C, et al. Systematic review of the effectiveness of stage based interventions to promote smoking cessation. BMJ 2003;326:1175-7.

51. Tobacco Cochrane Addiction Group. Glossary. 2014. http://tobacco. ochrane.org7glossary (accessed 11 Dec 2014).

52. West R, Hajek P, Stead L. Outcome criteria in smoking cessation trials: proposal for a common standard. Addiction 2005;100:299-303.

53. Society for Research on Nicotine and tobacco Europe. SRNT-Europe chapter recommendations. Record keeping for smoking cessation services. 2014. http://www.srnteurope.org/assets/ record-keeping-for-smoking-cessation-services.pdf. (accessed 11 Dec 2014). 